UDC 34:621.31

LBC 67.401.11

\title{
THE COMPARATIVE CHARACTERISTICS OF THE LEGAL REGULATION IN THE SPHERE OF THE ELECTRIC POWER INDUSTRY BY THE EXAMPLE OF THE RUSSIAN FEDERATION AND THE REPUBLIC OF KAZAKHSTAN
}

\author{
Elmira F. Baybekova \\ Astrakhan State University, Astrakhan, Russian Federation
}

\begin{abstract}
Introduction: the article is devoted to the legal regulation of the electric power industry in the Russian Federation and the Republic of Kazakhstan. For this purpose the author analyzes the development and ways of improvement of the legal regulation of the relations concerning the supply of energy and energy resources to the consumers that take place in the fuel and energy complex of Russia and Kazakhstan. With the help of the scientific methods, primarily the method of system and comparative analysis, the author analyzes the legislation of the Russian Federation and the Republic of Kazakhstan in the electric power industry to identify the gaps and shortcomings in the industry, since currently, the electric power industry is one of the main components of the fuel and energy complex of each state. Results: today the issues of the sphere of the electric power industry are of particular importance both for the contemporary global markets as a whole and for the Russian Federation. Their successful solution determines the need for the prospective improvement of the legal regulation of the relations in the fuel and energy sector both domestically and internationally. Conclusions: currently, there are many laws and statutory instruments for the legal regulation of the sphere of the electric power industry in this state and the Republic of Kazakhstan. In this regard, it is necessary to bring the energy legislation of the Russian Federation and the Republic of Kazakhstan into a single integrated system and to develop the system of the legal regulation of the transition of the electric power industry to the innovative way of development and the competitiveness of the countries.

Key words: electric power industry, electric power supply, reforms, government control, ways of improvement, laws and statutory instruments, world arena, fuel and energy complex.
\end{abstract}

\section{СРАВНИТЕЛЬНАЯ ХАРАКТЕРИСТИКА ЗАКОНОДАТЕЛЬНОГО РЕГУЛИРОВАНИЯ СФЕРЫ ЭЛЕКТРОЭНЕРГЕТИКИ НА ПРИМЕРЕ РОССИЙСКОЙ ФЕДЕРАЦИИ И РЕСПУБЛИКИ КАЗАХСТАН}

\author{
Эльмира Фаридовна Байбекова \\ Астраханский государственный университет, г. Астрахань, Российская Федерация
}

\begin{abstract}
Введение: статья посвящена правовому регулированию электроэнергетики в Российской Федерации и Республике Казахстан. С этой целью автором анализируются развитие и пути совершенствования законодательного регулирования отношений, касающихся снабжения потребителей энергией и энергоресурсами, тодов научного познания, прежде всего метода системного и сравнительного анализа, автором было проанализировано законодательство Российской Федерации и Республики Казахстан в сфере электроэнергетики одной из главных составляющих топливно-энергетического комплекса каждого государства. Результаты: сегодня вопросы сферы электроэнергетики приобретают особую значимость как для современной мировой площадки в целом, так и для Российской Федерации. Успешное их решение определяет необходимость перс(2) пективного совершенствования правового регулирования отношений в топливно-энергетическом секторе
\end{abstract}


как внутри страны, так и на международном уровне. Выводы: в настоящее время существует множество нормативных правовых актов для правового регулирования сферы электроэнергетики в нашем государстве и Республике Казахстан. В связи с этим необходимы приведение энергетического законодательства Российской Федерации и Республики Казахстан в единую целостную систему и разработка системы правового регулирования процессов перехода электроэнергетики на инновационный путь развития и повышение конкурентоспособности стран.

Ключевые слова: электроэнергетика, электроснабжение, реформы, государственное регулирование, пути совершенствования, нормативные правовые акты, мировая арена, топливно-энергетический комплекс.

\section{Введение}

Электроэнергетика в силу своей возрастающей актуальности становится площадкой, которая привлекает внимание не только всего общества, но и многих суверенных государств. Данное обстоятельство объясняется резким изменением стоимости на энергоносители, а также проблемами надежности поставок и задачами по обеспечению энергетической безопасности стран, применению новых источников энергии, ее экономией и экологическими последствиями неправильного обращения с энергоресурсами. Успешное решение вышеуказанных проблем обусловливает необходимость совершенствования законодательного регулирования отношений, касающихся снабжения потребителей энергией и энергоресурсами, которые возникают в топливно-энергетическом комплексе России [7]. Совершенствование законодательства России в энергетической сфере является одной из основных задач и курсов осуществления энергетической стратегии. Любые институциональные, экономические и другие преобразования в энергетике страны, а также построение внутренней и внешней политики в этой области должны базироваться исключительно на положениях нормативных правовых актов Российской Федерации.

\section{Основы правового регулирования сферы электроэнергетики В Российской Федерации}

С начала 90-х гг. ХХ столетия в России возникла настоятельная потребность в создании нормативно-правовой базы в энергетической области, что было определено интенсивным развитием рыночных отношений в таком немаловажном секторе экономики, как энергетика, которая включает в себя электроэнергетику, теплоэнергетику, нефтегазовый комп- лекс и другие значимые сферы экономики. В связи с этим специальная роль в решении проблемы развития вышеуказанных областей, безусловно, отводится государству в рамках правового регулирования отношений [2].

Основным нормативным правовым актом, в котором было предусмотрено пошаговое реформирование электроэнергетики России, явилось Постановление Правительства РФ от 11 июля 2001 г. № 526 «О реформировании электроэнергетики РФ». Данным документом были одобрены существенные направления реформирования электроэнергетики России. Для проведения структурных реформ в электроэнергетике РФ был принят целый ряд нормативных правовых актов, которые регулировали реформирование всей сферы [4]. Главными нормативными правовыми актами, которые заложили основу реформирования и дальнейшего развития электроэнергетики России, стали Федеральный закон от 26 марта 2003 г. № 36-Ф3 «Об особенностях функционирования электроэнергетики в переходный период» [8] и Федеральный закон от 26 марта 2003 г. № 35-Ф3 «Об электроэнергетике» [9]. С целью создания правовых условий реформирования электроэнергетики Российской Федерации законодателем были внесены изменения в Гражданский кодекс РФ, Федеральный закон от 26 декабря 1995 г. № 208-Ф3 «Об акционерных обществах», Федеральный закон от 14 апреля 1995 г. № 41-Ф3 «О государственном регулировании тарифов на электрическую и тепловую энергию в Российской Федерации», Федеральный закон от 3 апреля 1996 г. № 28-Ф3 «Об энергосбережении», Федеральный закон от 8 августа 2001 г. № 128-Ф3 «О лицензировании отдельных видов деятельности». Основной модификацией стало изменение, внесенное в § 6 («Энергоснабжение») главы 30 ч. 2 ГК РФ (п. 4 ст. 539): «К отношениям по договору энерго- 
снабжения электрической энергией правила настоящего параграфа применяются, если законом или иными правовыми актами не установлено иное» [1].

Для активизации создания необходимых законодательных норм в энергетической области 23 ноября 2009 г. был принят Федеральный закон № 261-Ф3 «Об энергосбережении и о повышении энергетической эффективности и о внесении изменений в отдельные законодательные акты Российской Федерации». В данном законодательном акте закрепились довольно обдуманные требования для обеспечения энергетической эффективности строений, зданий и сооружений, положения, которые касались повышения энергетической эффективности в жилищном фонде, и другие требования к осуществлению энергосберегающей деятельности [10].

Бесспорно, для исполнения вышеуказанного Закона была необходима его дальнейшая детализация в подзаконных нормативных правовых актах. В настоящее время существует Указ Президента РФ от 13 мая 2010 г. № 579 «Об оценке эффективности деятельности органов исполнительной власти субъектов РФ и органов местного самоуправления городских округов и муниципальных районов в области энергосбережения и повышения энергетической эффективности», рассматривающийся как инструмент контроля за реализацией положений об энергоэффективности [5].

Важнейшим фундаментом информационно-аналитического обеспечения формирования российской энергетики стал Федеральный закон от 3 декабря 2011 г. № 382-Ф3 «О государственной информационной системе топливно-энергетического комплекса», который вступил в силу 1 января 2012 года [6]. Его принятие - итог продолжительной работы по устранению противоречий и недостатков в нормативно-правовой базе, вызванных отсутствием системного подхода к правовому регулированию формирования и использования государственных информационных ресурсов топливно-энергетического комплекса. До вступления в силу закона № 382-Ф3 в законодательстве Российской Федерации отсутствовала необходимая законодательная основа, которая регламентировала бы комплексный подход по обеспечению государственных органов ин- формацией о состоянии и прогнозе развития топливно-энергетического комплекса. Исполнение закона № 382-Ф3 содействовало системности действий субъектов энергетической политики, а также обеспечению сбора, обработки информации о состоянии и прогнозе развития топливно-энергетического комплекса для ее вовлечения в область государственного управления и социально-экономического прогнозирования развития топливно-энергетического комплекса. Целью принятия закона № 382-Ф3 являлось формирование законодательных и организационных основ для обеспечения заинтересованных государственных органов, органов местного самоуправления, должностных лиц, организаций и граждан информацией о состоянии и прогнозе развития топливно-энергетического комплекса.

\section{Нормативно-правовая база Республики Казахстан в области электроэнергетики}

Что касается Казахстана, то в силу своей еще молодой и независимой истории республика только делает свои первоначальные шаги к достижению стабильного и непрерывного регулирования своего энергетического потенциала.

Природа одарила Казахстан природными ресурсами, в первую очередь энергетическими. За четверть века с момента обретения независимости страна добилась огромного прогресса в топливно-энергетическом комплексе: добыча нефти выросла в три раза и Казахстан надежно закрепил свои позиции на мировом рынке энергоресурсов. Эти достижения вносят огромный вклад в экономическое и социальное развитие страны [3].

Доходы от продажи продукции областей топливно-энергетического комплекса позволяют энергично формировать инфраструктуру Республики Казахстан, реализовывать трансфер передовых технологий, способствовать инновационному развитию экономики, гарантировать занятость значительной части трудоспособного населения, способствовать формированию социальной области.

В Республике Казахстан государство играет центральную роль в поддержке инициатив по повышению энергоэффективности, 
причем реализуемые при этом функции носят разноплановый характер: это и правовая поддержка, и организация нормативно-правовой базы, и экономическое стимулирование мер по энергосбережению и повышению энергоэффективности.

Важнейшим органом, который несет ответственность за реализуемую в стране политику в сфере энергетики, является министерство энергетики, принявшее на себя функции регулятора в данной сфере после ликвидации министерства индустрии и новых технологий, при этом отрасль энергоэффективности находится в ведении министерства по инвестициям и развитию. Политика государства, обеспечивающая повышение энергоэффективности, в основном ориентирована на модернизацию разнообразных сфер экономики, где потребляются основные объемы энергоресурсов [3].

Осуществляемая в настоящее время политика сформирована на следующих нормативных правовых актах:

- Закон Республики Казахстан от 9 июля 2004 г. «Об электроэнергетике»;

- Закон Республики Казахстан от 25 декабря 2008 г. «О конкуренции»;

- Закон Республики Казахстан от 4 июля 2009 г. «О поддержке использования возобновляемых источников энергии»;

- Закон Республики Казахстан от 9 января 2012 г. «О государственной поддержке индустриально-инновационной деятельности»;

- Постановление Правительства Республики Казахстан от 28 июня 2014 г. № 724 «Об утверждении Концепции развития топливноэнергетического комплекса Республики Казахстан до 2030 года».

Сегодня на первый план государственной политики Республики Казахстан выходит разработка и принятие стимулирующих энергосбережение механизмов. Хотя государство и так уже выдает гранты на пилотные и презентационные проекты, избирательно финансирует внедрение энергосберегающих технологий, но возможности для кредитования и предоставления налоговых преференций для поддержки проектов по энергосбережению использованы далеко не полностью.

Для Казахстана важно сохранить поступательное движение в части внедрения сти- мулирующих механизмов, поскольку действующее законодательство, в целом ориентированное на запреты и ограничения, сдерживает возможности по достижению значительного роста энергоэффективности.

Также необходимо обратить внимание на то, что в электроэнергетике необходимо сделать упор на нормативно-правовую базу по обеспечению надежности электроснабжения и повышению качества поставок электроэнергии (обязательные условия повышения энергоэффективности), включая введение механизма сертификации электроэнергии.

В республике полным ходом идет реализация стратегии «Казахстан-2050: новый политический курс состоявшегося государства», в рамках которой значительное внимание уделяется альтернативным и возобновляемым источникам энергии. По заявлению президента Нурсултана Назарбаева к 2050 г. на данные виды энергии должно приходиться не менее половины всего совокупного энергопотребления. В будущем традиционным источникам энергии составит конкуренцию новый возобновляемый источник, и получит ли он свое развитие или нет, покажут ближайшие годы [3].

\section{Выводы}

На основании вышеизложенного можно сделать следующие выводы:

1. Таким образом, за относительно короткий срок было создано новое российское законодательство об электроэнергетике. Для реализации законов Правительством Российской Федерации было принято более 20 нормативных правовых актов, которые регулируют отношения на конкурентном рынке электроэнергии. В настоящее время для нашего государства становится актуальным поиск национальной модели регулирования энергетических областей с учетом происходящей глобализации отношений в этих отраслях, поэтому важен как национальный опыт регулирования, так и международный.

2. В электроэнергетической сфере Республики Казахстан в дальнейшем необходимо сделать акцент на законодательную базу, в частности по обеспечению надежности электроснабжения и повышению качества поставок электроэнергии. 


\section{СПИСОК ЛИТЕРАТУРЫ}

1. Гражданский кодекс Российской Федерации (часть вторая) от 26 янв. 1996 г. № 14-Ф3 : (в ред. от 28 марта 2017 г.) // Собрание законодательства РФ. - 1996. - 29 янв. - № 5. - Ст. 410.

2. Михалев, Д. Н. Система договоров в сфере электроэнергетики / Д. Н. Михалев // Вестник Волгоградского государственного университета. Серия 5, Юриспруденция. -2011. - №2 (15). - С. 238-244.

3. Национальный энергетический доклад «KAZENERDGY». - 2015. - 420 с. - Электрон. текстовые дан. - Режим доступа: http://www.kazenergy.com. Загл. с экрана.

4. Постановление Правительства РФ «О реформировании электроэнергетики РФ» от 11 июля 2001 г. № 526 : (в ред. от 20 марта 2013 г.) // Собрание законодательства РФ. - 2001. - № 29. - Ст. 3032.

5. Указ Президента РФ «Об оценке эффективности деятельности органов исполнительной власти субъектов РФ и органов местного самоуправления городских округов и муниципальных районов в области энергосбережения и повышения энергетической эффективности» от 13 мая 2010 г. № 579 : (в ред. от 14 окт. 2012 г.) // Собрание законодательства Российской Федерации. - 2010. - 17 мая. - № 20. - Ст. 2432.

6. Федеральный закон «О государственной информационной системе топливно-энергетического комплекса» от 3 дек. 2011 г. № 382-Ф3 // Российская газета. - 2011. - 9 дек. (№ 5654 (278)).

7. Федеральный закон «О естественных монополиях» от 17 авг. 1995 г. № 147-Ф3 // Собрание законодательства РФ. - 1995. - № 3-4. - Ст. 3426.

8. Федеральный закон «Об особенностях функционирования электроэнергетики в переходный период» от 26 марта 2003 г. № 36-Ф3 : (в ред. от 29 дек. 2014 г.) // Собрание законодательства РФ. 2003. - 31 марта. - № 13. - Ст. 1178.

9. Федеральный закон «Об электроэнергетике» от 26 марта 2003 г. № 35-Ф3 // Собрание законодательства РФ. - 2003. - № 13. - Ст. 1177.

10. Федеральный закон «Об энергосбережении и о повышении энергетической эффективности и о внесении изменений в отдельные законодательные акты Российской Федерации» от 23 нояб. 2009 г. № 261-Ф3 : (в ред. от 3 июля 2016 г.) // Собрание законодательства РФ. - 2009. - 30 нояб. - № 48. - СТ. 5711.

11. Электроэнергетика России в период до 2030 года: контуры желаемого будущего. - М. : ИНЭИ, 2012. - 327 с.

\section{REFERENCES}

1. Grazhdanskiy kodeks Rossiyskoy Federatsii (chast vtoraya) ot 26 yanv. 1996 g. № 14-FZ: (v red. ot
28 marta 2017 g.) [The Civil Code of the Russian Federation (Part Two) of January 26, 1996 no. 14-FL: (amend. of March 28, 2017)]. Sobranie zakonodatelstva RF [Collected Legislation of the Russian Federation], 1996, Jan. 29, no. 5, art. 410.

2. Mikhalev D.N. Sistema dogovorov v sfere elektroenergetiki [The System of Contracts in the Electric Power Industry]. Vestnik Volgogradskogo gosudarstvennogo universiteta. Seriya 5, Yurisprudentsiya [Science Journal of Volgograd State University. Jurisprudence], 2011, no. 2 (15), pp. 238-244.

3. Natsionalnyy energeticheskiy doklad «KAZENERDGY» [KAZENERDGY National Energy Report], 2015. 420 p. URL: http://www.kazenergy.com.

4. Postanovlenie Pravitelstva RF «O reformirovanii elektroenergetiki $R F »$ ot 11 iyulya 2001 g. № 526: (v red. ot 20 marta 2013 g.) [Decree of the Government of the Russian Federation "On Reforming the Electric Power Industry of the Russian Federation" of July 11, 2001 no. 526: (amend. of March 20, 2013)]. Sobranie zakonodatelstva RF [Collected Legislation of the Russian Federation], 2001, no. 29, art. 3032 .

5. Ukaz Prezidenta RF «Ob otsenke effektivnosti deyatelnosti organov ispolnitelnoy vlasti subyektov RF i organov mestnogo samoupravleniya gorodskikh okrugov i munitsipalnykh rayonov v oblasti energosberezheniya i povysheniya energeticheskoy effektivnosti» ot 13 maya 2010 g. № 579: (v red. ot 14 okt. 2012 g.) [Decree of the President of the Russian Federation "On Assessing the Effectiveness of Executive Authorities of the Subjects of the Russian Federation and Local Self-Government Bodies of Urban Districts and Municipal Regions in the Field of Energy Conservation and Energy Efficiency" of May 13, 2010 no. 579: (as amended on October 14, 2012)]. Sobranie zakonodatelstva Rossiyskoy Federatsii [Collected Legislation of the Russian Federation], 2010, May 17, no. 20, art. 2432.

6. Federalnyy zakon «O gosudarstvennoy informatsionnoy sisteme toplivno-energeticheskogo kompleksa» ot 3 dek. 2011 g. № 382-FZ [The Federal Law "On State Information System of the Fuel and Energy Complex" of December 3, 2011 no. 382-FL]. Rossiyskaya gazeta, 2011, Dec. 9 (no. 5654 (278)).

7. Federalnyy zakon «O estestvennykh monopoliyakh» ot 17 avg. 1995 g. № 147-FZ [The Federal Law “On Natural Monopolies" of August 17, 1995 no. 147-FL]. Sobranie zakonodatelstva RF [Collected Legislation of the Russian Federation], 1995, no. 3-4, art. 3426.

8. Federalnyy zakon «Ob osobennostyakh funktsionirovaniya elektroenergetiki v perekhodnyy period» ot 26 marta 2003 g. № 36-FZ: (v red. ot 29 dek. 2014 g.) [The Federal Law "On Specific Features of the Electric Power Industry in the Transition Period" of 
March 26, 2003 no. 36-FL: (as amended on December 29, 2014)]. Sobranie zakonodatelstva RF [Collected Legislation of the Russian Federation], 2003, March 31 , no. 13 , art. 1178 .

9. Federalnyy zakon «Ob elektroenergetike» ot 26 marta 2003 g. № 35-FZ [The Federal Law “On Electric Power Industry” of March 26, 2003 no. 35-FL]. Sobranie zakonodatelstva RF [Collected Legislation of the Russian Federation], 2003, no. 13, art. 1177.

10. Federalnyy zakon «Ob energosberezhenii i o povyshenii energeticheskoy effektivnosti i o vnesenii izmeneniy v otdelnye zakonodatelnye akty Rossiyskoy
Federatsii» ot 23 noyab. 2009g. №261-FZ: (vred. ot 3 iyulya 2016 g.) [The Federal Law “On Energy Saving and Improving Energy Efficiency and on Amending Certain Legislative Acts of the Russian Federation" of November 23,2009 no. 261-FL: (as amended on July3, 2016)]. Sobranie zakonodatelstva $R F$ [Collected Legislation of the Russian Federation], 2009, Nov. 30, no. 48, art. 5711.

11. Elektroenergetika Rossii v period do 2030 goda: kontury zhelaemogo budushchego [Electric Power Industry in Russia in the Period till 2030: Contours of the Desired Future]. Moscow, INEI Publ., 2012.327 p.

\section{Information about the Author}

Elmira F. Baybekova, Candidate of Juridical Sciences, Associate Professor, Department of Civil Law, Astrakhan State University, Tatishcheva St., 20a, 414056 Astrakhan, Russian Federation, karinbey@mail.ru.

\section{Информация об авторе}

Эльмира Фаридовна Байбекова, кандидат юридических наук, доцент кафедры гражданского права, Астраханский государственный университет, ул. Татищева, 20a, 414056 г. Астрахань, Российская Федерация, karinbey@mail.ru. 